Correspondence

Kasthuri Venkateswaran kjvenkat@jpl.nasa.gov

\section{Bacillus nealsonii sp. nov., isolated from a spacecraft-assembly facility, whose spores are $\gamma$-radiation resistant}

\author{
Kasthuri Venkateswaran, ${ }^{1}$ Michael Kempf, ${ }^{1}$ Fei Chen, ${ }^{1}$ Masataka Satomi, ${ }^{2}$ \\ Wayne Nicholson ${ }^{3}$ and Roger Kern ${ }^{1}$
}

\author{
${ }^{1}$ Biotechnology and Planetary Protection Group, Jet Propulsion Laboratory, California Institute \\ of Technology, Pasadena, CA 91109, USA \\ ${ }^{2}$ National Research Institute of Fisheries Science, Food Processing Division, Kanazawa-ku, \\ Yokohama-City, Kanagawa 236-8648, Japan \\ ${ }^{3}$ Department of Veterinary Science and Microbiology, University of Arizona, Tucson, AZ 85721 , \\ USA
}

One of the spore-formers isolated from a spacecraft-assembly facility, belonging to the genus Bacillus, is described on the basis of phenotypic characterization, 16S rDNA sequence analysis and DNA-DNA hybridization studies. It is a Gram-positive, facultatively anaerobic, rod-shaped eubacterium that produces endospores. The spores of this novel bacterial species exhibited resistance to UV, $\gamma$-radiation, $\mathrm{H}_{2} \mathrm{O}_{2}$ and desiccation. The $16 \mathrm{~S}$ rDNA sequence analysis revealed a clear affiliation between this strain and members of the low $\mathrm{G}+\mathrm{C}$ Firmicutes. High $16 \mathrm{~S}$ rDNA sequence similarity values were found with members of the genus Bacillus and this was supported by fatty acid profiles. The $16 \mathrm{~S}$ rDNA sequence similarity between strain $\mathrm{FO}-92^{\top}$ and Bacillus benzoevorans DSM $5391^{\top}$ was very high. However, molecular characterizations employing smallsubunit 16S rDNA sequences were at the limits of resolution for the differentiation of species in this genus, but DNA-DNA hybridization data support the proposal of $\mathrm{FO}-92^{\top}$ as Bacillus nealsonii sp. nov. (type strain is FO $-92^{\top}=$ ATCC BAA $-519^{\top}=$ DSM $15077^{\top}$ ).

\section{INTRODUCTION}

The main focus of the National Aeronautics and Space Administration's planetary-protection efforts is the development of cleaning and sterilization technologies for spacecraft preparation prior to launch. Knowledge of the microbial diversity of spacecraft-assembly facilities, as well as any extreme characteristics these microbes might possess, is essential to the development of these technologies. The spacecraft-assembly facilities can be considered extreme environments created by the controlled air circulation, low humidity and low-nutrient conditions found in these cleanrooms. A wide variety of micro-organisms can survive

Published online ahead of print on 5 July 2002 as DOI 10.1099/ ijs.0.02311-0.

Abbreviations: FAME, fatty acid methyl ester; JPL-SAF, Jet Propulsion Laboratory Spacecraft Assembly Facility.

The GenBank/EMBL/DDBJ accession number for the $16 \mathrm{~S}$ rDNA sequence of strain $\mathrm{FO}-92^{\top}$ is AF234863.

Images of the Jet Propulsion Laboratory Spacecraft Assembly Facility are available as supplementary data in IJSEM Online (http:// ijs.sgmjournals.org). under such conditions (Puleo et al., 1973, 1975, 1977; Venkateswaran et al., 2001).

In on-going investigations to determine and document possible microbial contamination on representative spacecraft components and accessories, several physiologically and phylogenetically novel micro-organisms were encountered (Venkateswaran et al., 2001). Witness plates made of spacecraft-quality stainless steel were exposed for $\sim 9$ months at a Jet Propulsion Laboratory Spacecraft Assembly Facility (JPL-SAF) and the particulate materials collected revealed the presence of novel Bacillus species. Microorganisms that exhibit resistance to an assortment of free radicals and conditions employed in emergent technologies for sterilization of spacecraft components are significant. Here, we describe Bacillus nealsonii, whose spores are resistant to UV, $\gamma$-radiation, $\mathrm{H}_{2} \mathrm{O}_{2}$ and desiccation.

\section{METHODS}

Sample preparation and isolation of microbes from a spacecraft-assembly facility. The dimensions of the JPL-SAF are $25 \mathrm{~m}$ wide, $36 \mathrm{~m}$ long and $15 \mathrm{~m}$ high. Relative humidity was controlled at $40 \pm 5 \%$ with a cap at $45 \%$ and the mean temperature was maintained at $20 \pm 5{ }^{\circ} \mathrm{C}$. This JPL-SAF was maintained by qualified 
contamination control personnel with periodic checks to ensure a class 100000 (the maximum number of particles of the size $>0.5 \mu \mathrm{m}$ per cubic foot of air) clean-room level. Stainless steel witness plates (type 304, no. 4 finish, $0.05-0.08 \mathrm{~cm}$ thick; size, $2.5 \times 5 \mathrm{~cm}$; Mechanical Workshop, JPL) were ultrasonically cleaned in acetone (5-10 $\mathrm{min})$ followed by 2-propanol (5-10 $\mathrm{min})$. After air drying, the plates were sterilized by heating at $175{ }^{\circ} \mathrm{C}$ for $2 \mathrm{~h}$. The pre-sterilized witness plates were exposed in JPL-SAF on stands about $2 \mathrm{~m}$ high. This minimized contamination from human exhalation and sweat and ensured collection of dust particles that were naturally falling onto the witness plates. After a 9-month exposure, all 20 witness plates were individually placed into $50 \mathrm{ml}$ polypropylene disposable sterile centrifuge tubes.

Microbial examination. Each retrieved witness plate was placed into $30 \mathrm{ml}$ of sterile phosphate-buffered $(\mathrm{pH} \mathrm{7 \cdot 2)}$ rinse solution (Anonymous, 1980). The plate and rinse solution were sonicated for $2 \min \left(25 \mathrm{kHz}, 0 \cdot 35 \mathrm{~W} \mathrm{~cm}^{-2}\right)$. The rinse solution was aseptically divided into two $15 \mathrm{ml}$ aliquots. One aliquot of the rinse solution, along with the witness plate, was subjected to heat-shock $\left(80^{\circ} \mathrm{C}\right.$ for $15 \mathrm{~min}$ ), while the other aliquot was not heated. Total aerobic counts in appropriate aliquots of samples were determined by the pour plate technique using tryptic soy agar (TSA; Difco) as the growth medium $\left(32{ }^{\circ} \mathrm{C}\right.$ for $3-7$ days). Type strains of different Bacillus species were procured from established culture collections and used as controls when necessary to validate the procedures.

Sporulation. Bacillus endospores were purified using the following two procedures. Cells of an overnight TSA culture were harvested, washed in sterile water and heat-shocked at $80{ }^{\circ} \mathrm{C}$ for $15 \mathrm{~min}$. The heat-shock procedure killed vegetative cells but not mature spores. The heat-shocked samples were grown overnight on Difco nutrient agar supplemented with 5 p.p.m. $\mathrm{MnSO}_{4}$ (MN agar), which triggers sporulation of the test microbe. About $200 \mu \mathrm{l}$ of the heat-shocked samples was spread onto multiple MN agar plates to harvest sufficient quantities of the test isolate. The cells grown on agar were washed in sterile water and the heat-shock procedure, followed by growth on MN agar, was repeated until $99 \%$ spores were obtained. The percentage of spores was determined by viewing the spore preparations using phase-contrast microscopy. Spores appear as bright bodies when viewed with a phase-contrast microscope. Purification of spores using this $\mathrm{MN}$ agar method resulted in the retention of a loosely attached extraneous layer around the spore coat. In addition, a nutrient broth sporulation medium (NSM) was used to produce spores (Nicholson \& Setlow, 1990; Schaeffer et al., 1965). A single purified colony of the strain to be sporulated was inoculated into liquid NSM. After $2-3$ days of growth at $32{ }^{\circ} \mathrm{C}$, the cultures were examined in wet mounts to determine the level of sporulation. Once the number of free spores in the culture was greater than the number of vegetative cells, the culture was harvested and the spores were purified. Spore purification was performed by treating the spores with lysozyme and washing with salt and detergent (Nicholson \& Setlow, 1990). The chemical treatments used in this method removed the extraneous layer surrounding the spore coat. The purified spores were resuspended in sterile deionized water, heat-shocked $\left(80^{\circ} \mathrm{C}\right.$ for $\left.15 \mathrm{~min}\right)$ and stored at $4{ }^{\circ} \mathrm{C}$ in glass tubes.

Microscopy. The refractile nature of the spores was examined by phase-contrast microscopy using an Olympus microscope (BX-60). A Field-Emission Environmental Scanning Electron Microscope (ESEM; Philips XL30) was also used. Very high resolution/magnification and an excellent signal to noise ratio in regular high vacuum was achieved due to the field-emission electron source. Nondestructive examination of spores and vegetative cells was possible using this microscope. Specimen preparation procedures, which usually lead to sample artifacts, are not necessary when using the ESEM. In addition, standard scanning and transmission electron microscopy were used to examine the surface details and crosssections, respectively, as per established methods (Cole \& Popkin, 1981).

Characterization of spores for various physical and chemical conditions. Radiation dosimetry at the $\mathrm{Co}^{60}$ source was performed using an ion chamber with accuracy to the US Bureau of Standards (Coss, 1999) standard. All irradiations were carried out in glass vials using spore samples in water. The spores $\left(10^{8}\right.$ spores $\mathrm{ml}^{-1}$ ) were exposed to both $1 \mathrm{Mrad}\left(50 \mathrm{rad} \mathrm{s}^{-1}\right.$ for $\left.330 \mathrm{~min}\right)$ and $0.5 \mathrm{Mrad}\left(25 \mathrm{rad} \mathrm{s}^{-1}\right.$ for $330 \mathrm{~min}$.) and survival was quantitatively verified by growing the $\gamma$-radiation treated samples in TSA at $32{ }^{\circ} \mathrm{C}$.

Purified spores were diluted in PBS ( $\mathrm{pH} 7 \cdot 2$ ), placed into an uncovered Petri dish and exposed to UV radiation ( $254 \mathrm{~nm}$; UV Products). At appropriate intervals, samples of spores were removed, diluted serially 10 -fold in PBS and plated onto NSM agar. Plates were incubated at $37^{\circ} \mathrm{C}$ for up to 5 days and colonies were counted.

A liquid $\mathrm{H}_{2} \mathrm{O}_{2}$ protocol, developed by Riesenman \& Nicholson (2000), was modified and used to examine $\mathrm{H}_{2} \mathrm{O}_{2}$ resistance in spores. Suitable aliquots of spore suspensions prepared in PBS were treated with $\mathrm{H}_{2} \mathrm{O}_{2}$ ( $5 \%$ final concentration) and incubated at room temperature $\left(\sim 25^{\circ} \mathrm{C}\right)$ with gentle mixing. After $60 \mathrm{~min}$ incubation, a $100 \mu \mathrm{l}$ sample was removed and diluted in a solution of bovine catalase $\left(100 \mu \mathrm{g} \mathrm{ml}^{-1}\right.$ in PBS). Serial $1: 10$ dilutions of the catalase-treated suspension were prepared in tryptic soy broth (TSB; Difco) to check viability and spread onto TSA for quantitative measurement of the $\mathrm{H}_{2} \mathrm{O}_{2}$-resistant spores.

For desiccation resistance, the spore suspension $(20 \mu \mathrm{l})$ was dispensed onto pre-sterilized metals and glass-fibre discs $\left(10^{3}\right.$ spores per disc; Millipore). After removing most of the water content by drying at room temperature ( $\sim 40-50 \%$ humidity in Pasadena, CA, USA) for 1 or 2 days, the colonies were counted on TSA medium. Briefly, the desiccated sample was placed in sterile PBS, mixed thoroughly and sonicated for $2 \mathrm{~min}$ before plating onto TSA medium. Plates were incubated at $32{ }^{\circ} \mathrm{C}$ for 2 days and the number of spores that survived was counted.

\section{Identification}

Phenotypic characterization and fatty acid analysis. Routine biochemical tests were carried out according to established procedures (Claus \& Berkeley, 1986; Priest, 1993). The ability to grow at a $\mathrm{NaCl}$ concentration of $1-10 \%$ was determined in $\mathrm{T}_{1} \mathrm{~N}_{1}$ liquid medium $(1 \%$ Bacto tryptone and appropriate amount of $\mathrm{NaCl})$ and the ability to grow without $\mathrm{NaCl}$ was determined in $1 \%$ sterile tryptone water. The API CHB 50 kit and API 20E (bioMérieux) were used ( 75 biochemical tests). Identification of the test isolate was carried out by computing and comparing biochemical test results from the bioMerieux database. In addition, the commercially available Biolog identification system was also used, according to manufacturer's specifications. Fatty acid methyl ester (FAME) profiles were examined from overnight cultures grown at $32{ }^{\circ} \mathrm{C}$ in TSB, as described previously (Ringelberg et al., 1994).

16S rDNA sequencing. Purified genomic DNA (Johnson, 1981) from liquid cultures was quantified and $\sim 10$ ng of DNA was used as the template for PCR amplification. Universal primers (Bact 11 and 1,492 ) were used to amplify the $1.5 \mathrm{~kb}$ PCR fragment by protocols established by Ruimy et al. (1994). Amplicons were sequenced directly following purification on Qiagen columns. The identity of a given PCR product was verified by sequencing using the dideoxy chain termination method with the Sequenase DNA sequencing kit (United States Biochemical) and an ABI 373A automated sequencer (Perkin-Elmer). The phylogenetic relationships of organisms covered 
in this study were determined by comparison of individual $16 \mathrm{~S}$ rDNA sequences to other existing sequences in GenBank. Evolutionary trees were constructed using PAUP (Swofford, 1990).

DNA-DNA hybridization. Cells were suspended in $0 \cdot 1 \mathrm{M}$ EDTA $(\mathrm{pH} 8 \cdot 0)$ and digestion of the cell wall was carried out by treating the cells with lysozyme (final concentration, $2 \mathrm{mg} \mathrm{ml}^{-1}$ ). DNA was isolated by standard procedures (Johnson, 1981). DNA-DNA homology was studied by microplate hybridization methods (Ezaki et al., 1989) with photobiotin labelling and colorimetric detection, using 1,2-phenylenediamine (Sigma) as the substrate and streptavidineperoxidase conjugate (Boehringer Mannheim) as the colorimetric enzyme (Satomi et al., 1997).

\section{RESULTS AND DISCUSSION}

\section{Microbial and particle contamination of JPL-SAF}

Particles of the size 11-150 $\mu \mathrm{m}$ were collected on witness plates (Anonymous, 1989). The stainless steel witness plates accumulated mid-range size $(26-100 \mu \mathrm{m})$ particles and the abundance of particles decreased when the particle size decreased (data not shown). Microbial contamination transferred through particulate materials was not high, in terms of microbial load, in this well-controlled facility. The particles trapped on stainless steel witness plates harboured an equivalent number of both vegetative ( 5 c.f.u. $\mathrm{cm}^{-2}$ ) and spore-forming $\left(6 \pm 1\right.$ c.f.u. $\left.\mathrm{cm}^{-2}\right)$ microbes. When the isolated colonies were exposed to harsh conditions, such as UV, $\gamma$-radiation, $\mathrm{H}_{2} \mathrm{O}_{2}$ and desiccation, some sporeformers showed resistance. Among these spore-formers, a strain, designated as FO- $92^{\mathrm{T}}$, exhibited distinct spore morphology and was further characterized for its phylogenetic affiliation.

\section{Morphological and physiological characteristics}

Strain $\mathrm{FO}-92^{\mathrm{T}}$ is a Gram-positive, facultatively anaerobic, rod-shaped, spore-forming bacterium. Cells are $4-5 \mu \mathrm{m}$ in length, $1 \mu \mathrm{m}$ in diameter and are motile. On TSA medium incubated at $32{ }^{\circ} \mathrm{C}$, young colonies are beige, irregular, with a diameter of 3-4 mm, rough, umbonate with undulate or lobate edges. Endospores of strain $\mathrm{FO}-92^{\mathrm{T}}$ are oval $(1 \times 0.5 \mu \mathrm{m}$; Fig. 1a), with one spore per cell. Spores purified using the $\mathrm{MN}$ agar procedure contain a distinctive extraneous layer (Fig. 1b). Cross-sections of the MN agarpurified spores clearly show a loosely arranged layer outside the spore coat (Fig. 1c, d). This structure resembles the exosporium of the Bacillus cereus group (data not shown). This extraneous layer can be removed from the FO- $92^{\mathrm{T}}$ spores by washing with detergents and salts using the Nicholson \& Setlow (1990) protocol. Spores of Bacillus
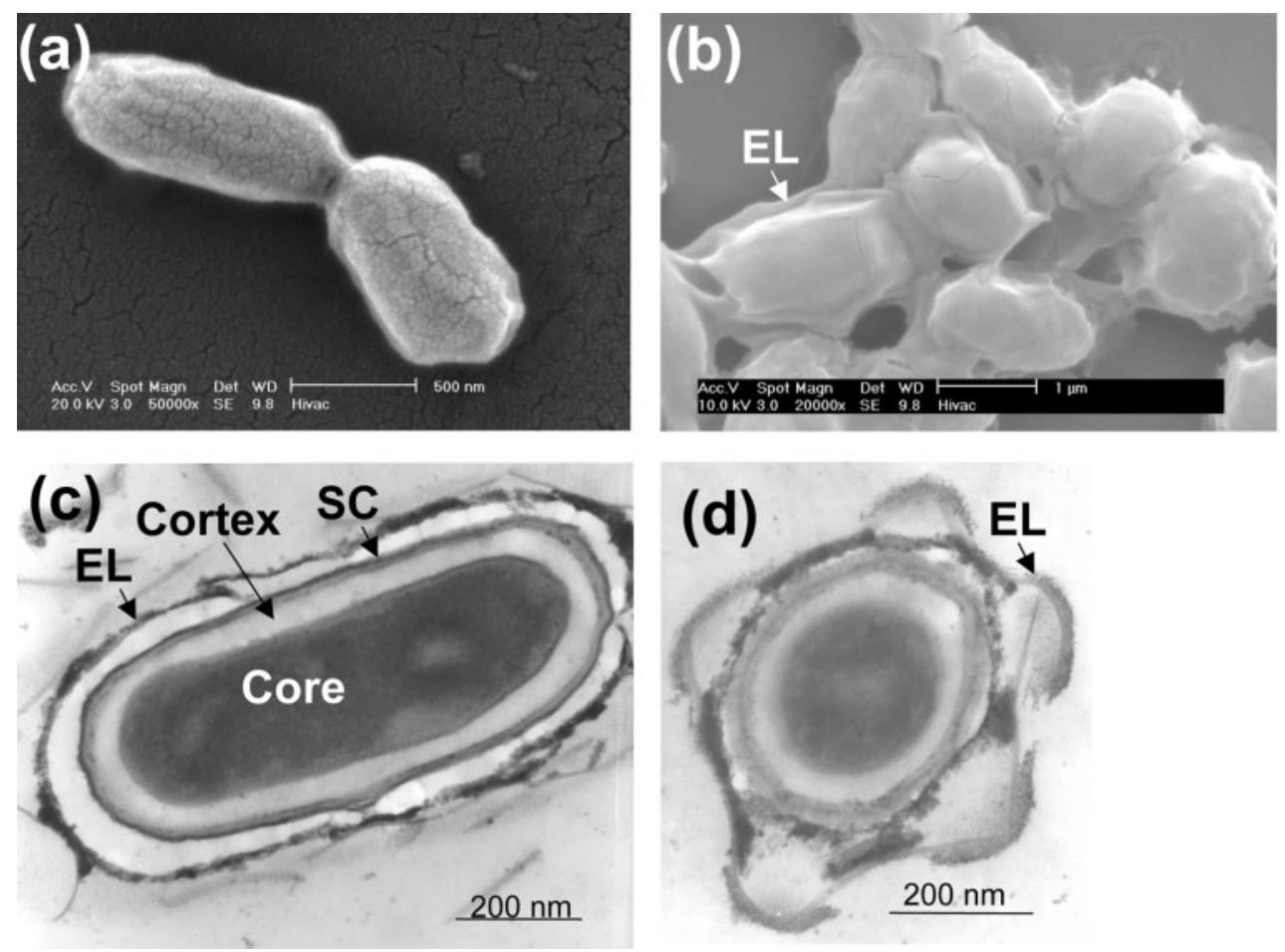

Fig. 1. Environmental scanning electron micrograph $(a, b)$ and transmission electron micrograph (c, d) of $B$. nea/sonii FO-92 ${ }^{\top}$ spores. Spores $(b-d)$ were purified on MN agar (see Methods). (a) Purified spores as per the protocol of Nicholson \& Setlow (1990); (b) MN agar-purified spores retaining the extraneous layer (EL); (c) longitudinal section of a spore where the extraneous layer (EL), spore coat (SC), cortex and spore core are shown; (d) cross-section of a spore where the loosely attached extraneous layer is observed. The extraneous layer was removed by salt and detergent washes (a). Cross-sections of spores purified according to the method of Nicholson \& Setlow (1990) did not possess the extraneous layer (data not shown). 
subtilis ATCC $6633^{\mathrm{T}}$, Bacillus pumilus ATCC $7061^{\mathrm{T}}$ and Bacillus megaterium IAM $13418^{\mathrm{T}}$ did not show an extraneous layer when purified from $\mathrm{MN}$ agar. The extra layer (exosporium) was retained in Bacillus cereus JCM $1252^{\mathrm{T}}$ and B. sphaericus $34 \mathrm{hs} 1$ even after the chemical treatments (Nicholson \& Setlow, 1990) used to purify the spores (data not shown). The characterization and the physiological role of this extraneous layer of strain $\mathrm{FO}-92^{\mathrm{T}}$ spores is not discussed in this paper. However, the resistance of the spores with and without extraneous layers against various treatments was measured.

\section{Resistance of FO- $92^{\mathrm{T}}$ spores to various physical and chemical conditions}

The resistance of Bacillus spores to a variety of conditions is common as seen in our control experiments (data not shown) and in other studies (for a review, see Nicholson et al., 2000). The spores of FO- $92^{\mathrm{T}}$ exhibited resistance to $0 \cdot 5$ $\operatorname{Mrad}(5 \mathrm{kGy}) \gamma$-radiation $\left(\mathrm{Co}^{60}\right), 200 \mathrm{~J} \mathrm{~m}^{-2} \mathrm{UV}(254 \mathrm{~nm})$, $5 \%$ liquid $\mathrm{H}_{2} \mathrm{O}_{2}$ and desiccation conditions. However, $1 \mathrm{Mrad} \gamma$-radiation was lethal and no spore germination was observed. Spores with the extraneous layer showed a 4-log reduction whereas spores without the extraneous layer showed a $5-\log$ reduction at $0.5 \mathrm{Mrad} \gamma$-radiation. Although preliminary experiments suggest a protective role of the extraneous layer against $\gamma$-radiation, more detailed studies are warranted. The FO- $92^{\mathrm{T}}$ spores exhibited classic UV inactivation kinetics, with a characteristic 'shoulder' extending to $\sim 100 \mathrm{~J} \mathrm{~m}^{-2}$, followed by strict exponential inactivation thereafter. $\mathrm{FO}-92^{\mathrm{T}}$ spores exhibited an $\mathrm{LD}_{90}$ value (the $90 \%$ lethal dose) of $\sim 200 \mathrm{~J} \mathrm{~m}^{-2}$ (Fig. 2), in good agreement with UV resistance values obtained for spores of the model organism, B. subtilis strain 168 (Nicholson et al., 2000). The vegetative cells of strain FO- $92^{\mathrm{T}}$ were resistant to $5 \%$ liquid $\mathrm{H}_{2} \mathrm{O}_{2}$ (data not shown). Purified spores that were

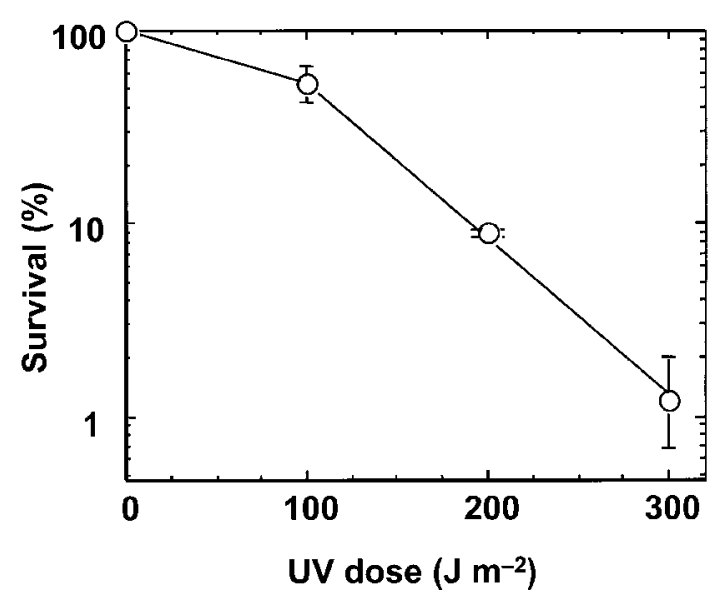

Fig. 2. Resistance of $\mathrm{FO}-92^{\top}$ spores to $254 \mathrm{~nm}$ UV radiation. Results shown are the means and standard deviations of three experiments. Spores purified by the Nicholson \& Setlow (1990) protocol were used in this experiment. exposed to 5\% liquid $\mathrm{H}_{2} \mathrm{O}_{2}$ for 30-60 min showed resistance, but prolonged incubation to $90 \mathrm{~min}$ eliminated the viability (data not shown).

\section{Optimum growth conditions}

Strain FO- $92^{\mathrm{T}}$ grew at $25-60{ }^{\circ} \mathrm{C}$, with optimum growth at $30-35^{\circ} \mathrm{C}$ and over the $\mathrm{pH}$ range of 6-10 (optimum 6-7). This strain did not require $\mathrm{Na}^{+}$for growth and was as desiccation resistant as other spore-formers. However, it is interesting to note that the centre of an overnight colony on TSA (at $32{ }^{\circ} \mathrm{C}$ ) predominantly consisted of spores when compared to the periphery of the colony (data not shown). Such an immediate response in triggering sporulation during nutrient-depleted conditions is common in Bacillus species. But, when compared to B. subtilis ATCC $6633^{\mathrm{T}}$, where spores were formed in 3-4 days on TSA (data not shown), strain FO- $92^{\mathrm{T}}$ produced spores in 1 day.

\section{Phenotypic characterization}

The biochemical characterization of strain $\mathrm{FO}-92^{\mathrm{T}}$ is presented in Table 1. In addition to the characters shown, strain $\mathrm{FO}-92^{\mathrm{T}}$ produced catalase but hydrogen sulfide was not produced from thiosulfite. The carbon substrate profile of FO- $92^{\mathrm{T}}$, as measured by the BioLog system, showed an identification match for Bacillus. Phenotypically, as measured by the API system, this strain resembles $B$. circulans ATCC $4513^{\mathrm{T}}$.

Bacillus species that produce acid from a variety of sugars, including glucose, are classified under rRNA group 1 (Priest, 1993). Most of these species were able to grow at least weakly in the absence of oxygen. Spores of these species were ellipsoidal and did not swell the mother cell. These species are considered the 'subtilis group' because of their similar physiological properties (Priest, 1993). Strain FO-92 ${ }^{\mathrm{T}}$, isolated from JPL-SAF, exhibited the characteristics necessary to place it into the rRNA group 1 .

\section{Cellular fatty acid composition}

Strain $\mathrm{FO}-92^{\mathrm{T}}$ contained straight-chain and terminally branched saturated and mono-unsaturated fatty acids with a composition of 18,73 and $9 \%$, respectively (Table 2). Among the fatty acids measured, tetradecanoic acid (14:0), 13-methyl pentadecanoic acid (15:0 iso) and 12-methyl tetradecanoic acid (15:0 anteiso) were the major fatty acids in FO-92 ${ }^{\mathrm{T}}$. This FAME profile identified strain $\mathrm{FO}-92^{\mathrm{T}}$ as Bacillus circulans DSM $11^{\mathrm{T}}$. FAME analysis of other Bacillus species showed distinct profiles. For example, Bacillus licheniformis ATCC $14580^{\mathrm{T}}$ contained $\sim 90 \%$ terminally branched saturated fatty acids, whereas Bacillus mycoides ATCC $6462^{\mathrm{T}}$ showed more monosaturated fatty acids. Although both $B$. subtilis IAM $1026^{\mathrm{T}}$ and strain FO- $92^{\mathrm{T}}$ exhibited high levels of straight-chain saturated fatty acids, B. subtilis IAM $1026^{\mathrm{T}}$ contained high levels of pentadecanoic 
Table 1. Biochemical characteristics of $B$. nealsonii FO$92^{\top}$ and related species

Strain: 1, B. licheniformis ATCC $14580^{\mathrm{T}} ; 2$, B. subtilis IAM $1026^{\mathrm{T}}$; 3, B. pumilus ATCC $7061^{\mathrm{T}}$; 4, B. mycoides ATCC $6462^{\mathrm{T}} ; 5, B$. circulans ATCC $4513^{\mathrm{T}}$; 6, B. firmus ATCC $14575^{\mathrm{T}}$; 7, B. nealsonii FO- $92^{\mathrm{T}}$. All strains are Gram-positive rods, facultatively anaerobic and do not denitrify. None produces lysine or ornithine decarboxylases, urease, tryptophan deaminase, hydrogen sulfide or indole. None utilizes glucose, inositol, sucrose, citrate, sorbitol, rhamnose, melibiose or arabinose as sole carbon source. All ferment L-arabinose, D-glucose, D-fructose, D-mannose, mannitol, methyl $\alpha$-D-glucoside, amygdalin, arbutin, aesculin, salicin, cellobiose, maltose, sucrose and trehalose. None ferments methyl $\alpha$-D-mannoside, inulin, xylitol, L-fucose, erythritol, L-xylose, methyl $\beta$-xyloside, L-sorbose, dulcitol, D-fucose, L-arabitol or 5-ketogluconate.

\begin{tabular}{|c|c|c|c|c|c|c|c|}
\hline Test & 1 & 2 & 3 & 4 & 5 & 6 & 7 \\
\hline \multicolumn{8}{|l|}{ Enzyme production: } \\
\hline$\beta$-Galactosidase & + & - & - & + & + & + & + \\
\hline Arginine dihydrolase & + & - & - & - & - & - & - \\
\hline Cytochrome oxidase & + & + & + & - & - & - & - \\
\hline Acetoin production & - & - & + & - & - & - & - \\
\hline Gelatin liquefication & - & + & - & - & - & - & - \\
\hline \multicolumn{8}{|l|}{ Utilization of: } \\
\hline Mannitol & - & - & - & - & + & + & - \\
\hline Amygdalin & - & - & + & - & + & - & - \\
\hline \multicolumn{8}{|l|}{ Fermentation of: } \\
\hline Glycerol & + & + & + & - & + & + & + \\
\hline Ribose & + & + & + & - & - & - & - \\
\hline D-Xylose & - & - & + & + & + & - & + \\
\hline Adonitol & - & + & - & - & - & - & - \\
\hline Galactose & - & - & + & - & + & - & + \\
\hline Rhamnose & - & - & - & - & - & - & + \\
\hline Inositol & + & + & + & - & + & - & + \\
\hline Sorbitol & + & + & - & - & + & - & + \\
\hline$N$-Acetylglucosamine & + & - & + & + & + & + & + \\
\hline Lactose & - & - & + & - & - & - & + \\
\hline Melibiose & - & + & + & - & + & - & + \\
\hline Melezitose & - & - & - & - & + & - & + \\
\hline Raffinose & - & + & - & - & - & - & + \\
\hline Starch & - & + & - & - & + & - & + \\
\hline Glycogen & - & + & - & - & + & - & - \\
\hline Gentiobiose & - & + & + & - & + & - & + \\
\hline D-Turanose & - & + & + & - & + & + & + \\
\hline D-Lyxose & - & - & - & - & + & - & + \\
\hline D-Tagatose & + & - & + & + & - & - & + \\
\hline D-Arabitol & - & - & - & - & - & - & + \\
\hline Gluconate & + & - & - & - & + & - & + \\
\hline 2-Ketogluconate & - & - & - & - & - & - & + \\
\hline
\end{tabular}

acid (15:0). Unfortunately, different culture conditions can result in high variability within FAME profiles (Venkateswaran et al., 1999). FAME analysis is ambiguous because type strains of some of the Bacillus species could not be identified correctly (Table 2). Because of these uncertainties, the identification of strain $\mathrm{FO}-92^{\mathrm{T}}$ could not be conclusively determined by fatty acid profiles.

\section{5 rDNA sequence analysis}

Molecular methods are less susceptible to artifactual misinterpretation than culture-based approaches. Studies have revealed that organisms with less than $97 \%$ similarity over the 16S rRNA gene do not yield DNA reassociation values of more than $60 \%$ (Stackebrandt \& Goebel, 1994). While the gene sequence of the small subunit of the $16 \mathrm{~S}$ rRNA molecule is acceptable for defining phylogenetic relationships between distinctly related organisms (Woese, 1987), this molecule at times lacks the specificity required for the differentiation of close relatives (Fox et al., 1992; Venkateswaran et al., 1998, 1999; Yamada et al., 1999). Strain FO- $92^{\mathrm{T}}$ closely resembled $B$. circulans by conventional phenotypic characterization and FAME profiles. In order to confirm the species identity, molecular phylogeny was carried out on this strain.

The $16 \mathrm{~S}$ rDNA sequences of all known Firmicutes were compared with that of FO- $92^{\mathrm{T}}$. All phylogenetic analyses, based on $16 \mathrm{~S}$ rDNA sequence, unambiguously demonstrated that FO- $92^{\mathrm{T}}$ belonged to the low $\mathrm{G}+\mathrm{C}$ Gram-positive bacteria. The $16 \mathrm{~S}$ rDNA sequences of all known members of the Gram-positive bacteria were compared with that of FO$92^{\mathrm{T}}$. Their phylogenetic relationships were then analysed and the study was repeated with several different subdomains of the 16S rDNA sequence. Bootstrapping (500 replicates) analysis was performed to avoid sampling artifacts. The resulting analyses indicated that $\mathrm{FO}-92^{\mathrm{T}}$ shares a close phylogenic relationship with Bacillus species. Neighbour-joining, parsimony and maximum-likelihood analyses were undertaken on this subset of bacteria, using several subdomains of the $16 \mathrm{~S}$ rDNA. In all analyses, FO- $92^{\mathrm{T}}$ was most closely associated with members of the genus Bacillus.

The similarities in the 16S rDNA nucleotide sequences between FO- $92^{\mathrm{T}}$ and the top 17 closely related Bacillus species, recognized by GenBank BLAST searches, were between 95 and $98.7 \%$. A sequence variation of $\sim 1 \%$ was found between FO- $92^{\mathrm{T}}$ and $B$. circulans ATCC $4513^{\mathrm{T}}$ and $2 \%$ between FO-92 ${ }^{\mathrm{T}}$ and Bacillus benzoevorans DSM $5391^{\mathrm{T}}$ as well as Bacillus firmus IAM 12464. A very high sequence variation $(5 \%)$ was noticed between $\mathrm{FO}-92^{\mathrm{T}}$ and both B. subtilis ATCC $6633^{\mathrm{T}}$ and B. pumilus OM-F6. Such a high degree of dissimilarity within a well-described genus is not uncommon.

A phylogenetic tree based on $16 \mathrm{~S}$ rDNA sequences is shown in Fig. 3. The branching order of this tree showed two distinct clusters in which one clade consisted of the $B$. subtilis group and another stock formed with 12 other species, including strain $\mathrm{FO}-92^{\mathrm{T}}$. These 12 other species exhibited five subclusters in which three major clades each contained at least three species. The first clade comprised FO- $92^{\mathrm{T}}$, B. circulans ATCC $4513^{\mathrm{T}}$ and B. benzoevorans DSM $5391^{\mathrm{T}}$. The second clade contained 'Bacillus macroides' strain dhr2, Bacillus fumarioli LMG 17492 and Bacillus niacini IFO $15566^{\mathrm{T}}$, and the third clade included Bacillus 
Table 2. Fatty acid methyl ester composition (\%) of $B$. nealsonii FO- $92^{\top}$ and related species

Strain: 1, B. circulans DSM $11^{\mathrm{T}}$; 2, B. firmus DSM $12^{\mathrm{T}} ; 3$, B. megaterium DSM $32^{\mathrm{T}} ; 4$, B. simplex DSM 1321; 5, B. pumilus DSM $27^{\mathrm{T}}$; 6, B. subtilis DSM $10^{\mathrm{T}} ; 7$, B. subtilis IAM $1026^{\mathrm{T}} ; 8$, B. licheniformis ATCC $14580^{\mathrm{T}} ; 9$, B. mycoides ATCC $6462^{\mathrm{T}} ; 10$, B. nealsonii FO-092 ${ }^{\mathrm{T}}$.

\begin{tabular}{|c|c|c|c|c|c|c|c|c|c|c|}
\hline Fatty acid & $1^{\star}$ & $2^{\star}$ & $3^{\star}$ & $4^{\star}$ & $5^{*}$ & $6^{*}$ & 7 & 8 & 9 & 10 \\
\hline $14: 0$ & $2 \cdot 9$ & $1 \cdot 1$ & $1 \cdot 6$ & $1 \cdot 5$ & $0 \cdot 5$ & $0 \cdot 2$ & $1 \cdot 1$ & & $3 \cdot 0$ & $12 \cdot 3$ \\
\hline $16: 0$ & $2 \cdot 7$ & $1 \cdot 5$ & $2 \cdot 6$ & $4 \cdot 1$ & $1 \cdot 4$ & $2 \cdot 0$ & $10 \cdot 2$ & $5 \cdot 3$ & $6 \cdot 2$ & $5 \cdot 2$ \\
\hline $18: 0$ & & $0 \cdot 1$ & & & $0 \cdot 1$ & & $1 \cdot 0$ & & & \\
\hline $13: 0$ iso & $0 \cdot 2$ & & & & $0 \cdot 1$ & $0 \cdot 1$ & & & $7 \cdot 6$ & $2 \cdot 9$ \\
\hline $14: 0$ iso & $4 \cdot 0$ & $2 \cdot 4$ & $6 \cdot 0$ & $3 \cdot 2$ & $0 \cdot 7$ & $0 \cdot 9$ & $2 \cdot 3$ & $1 \cdot 0$ & $5 \cdot 0$ & $6 \cdot 6$ \\
\hline $15: 0$ iso & $13 \cdot 9$ & $45 \cdot 8$ & $33 \cdot 6$ & $9 \cdot 3$ & $56 \cdot 9$ & $33 \cdot 1$ & $13 \cdot 2$ & $19 \cdot 7$ & $20 \cdot 9$ & $26 \cdot 4$ \\
\hline $16: 0$ iso & $4 \cdot 4$ & $2 \cdot 9$ & $0 \cdot 9$ & & $1 \cdot 4$ & $2 \cdot 0$ & $4 \cdot 6$ & $4 \cdot 8$ & $10 \cdot 2$ & $2 \cdot 1$ \\
\hline $17: 0$ iso & $1 \cdot 3$ & $2 \cdot 9$ & $1 \cdot 3$ & $1 \cdot 0$ & $5 \cdot 2$ & $10 \cdot 5$ & $7 \cdot 8$ & $6 \cdot 3$ & $6 \cdot 9$ & \\
\hline \multicolumn{11}{|l|}{ Mono-unsaturated } \\
\hline $16: 1 \omega 7 c$ alcohol & $0 \cdot 2$ & $4 \cdot 5$ & $0 \cdot 9$ & $1 \cdot 8$ & $0 \cdot 4$ & $0 \cdot 1$ & & & $4 \cdot 6$ & $1 \cdot 8$ \\
\hline $16: 1 \omega 11 c$ & $2 \cdot 6$ & $3 \cdot 2$ & $2 \cdot 9$ & $2 \cdot 3$ & $1 \cdot 0$ & $1 \cdot 2$ & $4 \cdot 8$ & $2 \cdot 1$ & $4 \cdot 0$ & $7 \cdot 5$ \\
\hline iso $17: 1 \omega 10 c$ & $0 \cdot 1$ & $0 \cdot 1$ & & & & & $1 \cdot 6$ & $1 \cdot 4$ & $11 \cdot 8$ & \\
\hline Sum of $15: 0$ iso $2-\mathrm{OH} / 16: 1 \omega 7 c$ & $0 \cdot 8$ & $1 \cdot 2$ & $1 \cdot 0$ & $1 \cdot 8$ & $0 \cdot 6$ & $0 \cdot 5$ & & & $7 \cdot 1$ & \\
\hline Sum of $17: 1$ anteiso B/iso I & $0 \cdot 3$ & $7 \cdot 2$ & $0 \cdot 9$ & $1 \cdot 0$ & $4 \cdot 3$ & $4 \cdot 7$ & $1 \cdot 2$ & $2 \cdot 0$ & $2 \cdot 7$ & \\
\hline
\end{tabular}

${ }^{\star}$ Data from Kämpfer (1994).

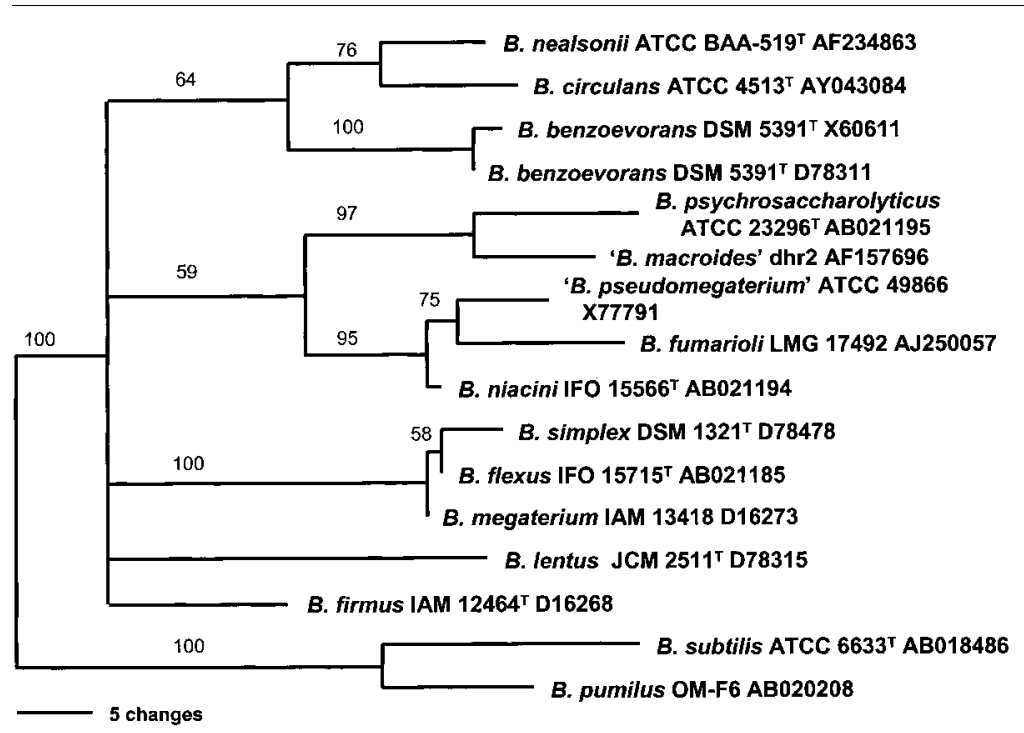

Fig. 3. Phylogenetic tree of various species of Bacillus based on 16S rDNA nucleotide sequences. The numbers after the name of the bacteria are the GenBank nucleotide accession numbers and the numbers above the lines are the percentage bootstrap values of that branch of the tree.

simplex DSM $1321^{\mathrm{T}}$, Bacillus flexus IFO $15715^{\mathrm{T}}$ and Bacillus megaterium IAM 13418. Because of the inadequacy of $16 \mathrm{~S}$ rDNA analysis for species differentiation, DNA-DNA hybridization was performed.

\section{DNA-DNA hybridization}

DNA-DNA hybridization was performed between FO- $92^{\mathrm{T}}$ and 18 strains, comprising 12 Bacillus species. None of the
Bacillus species that showed very high similarities with the $16 \mathrm{~S}$ rDNA sequences ( $97 \%$ ) exhibited $>70 \%$ DNA-DNA reassociation values that would place the strain within the same species. Particularly, the similarity between FO- $92^{\mathrm{T}}$ and $B$. circulans ATCC $4513^{\mathrm{T}}$ was only $16 \%$. This pair showed $98 \cdot 7 \%$ similarity in their $16 \mathrm{~S}$ rDNA sequences. Similarly, FO-92 ${ }^{\mathrm{T}}$ and B. benzoevorans ATCC $49005^{\mathrm{T}}$ showed only $15 \%$ DNA-DNA hybridization values whereas 
this pair exhibited $\sim 98 \%$ similarity in their $16 \mathrm{~S}$ rDNA sequence. Based on the DNA-DNA reassociation values, FO- $92^{\mathrm{T}}$ is a novel Bacillus species.

\section{Description of Bacillus nealsonii sp. nov.}

Bacillus nealsonii (neal'son.i.i. N.L. gen. n. nealsonii referring to Kenneth $\mathrm{H}$. Nealson, a well-known American microbiologist).

Cells are rod-shaped, $4-5 \mu \mathrm{m}$ in length, $1 \mu \mathrm{m}$ in diameter and motile. Gram-positive, facultatively anaerobic and forms endospores. Spores show an additional extraneous layer similar to an exosporium. Colonies on TSA are irregular, rough, umbonate with undulate or lobate edges and beige in colour. Sodium ions are not essential and it grows at $0-8 \% \mathrm{NaCl}$. Grows at $\mathrm{pH} 6-10$, optimum $\mathrm{pH} 7$. Grows at $25-60{ }^{\circ} \mathrm{C}$, optimum $30-35^{\circ} \mathrm{C}$. Catalase and $\beta$-galactosidase are produced, but gelatinase, arginine dihydrolase, lysine and ornithine decarboxylases, lipase, amylase and alginase are not. It neither produces $\mathrm{H}_{2} \mathrm{~S}$ from thiosulfite nor denitrifies. Based on 16S rDNA nucleotide sequences, this bacterium belongs to the class Firmicutes and is a member of the genus Bacillus. The type strain, FO- $92^{\mathrm{T}}\left(=\right.$ ATCC BAA $-519^{\mathrm{T}}=$ DSM $\left.15077^{\mathrm{T}}\right)$, was isolated from dust particles collected at the Jet Propulsion Laboratory Spacecraft Assembly Facility.

\section{ACKNOWLEDGEMENTS}

We thank S. Chung, C. Echeverria, R. Koukol, L. Link, M. Musick, J. Sawyer and $\mathrm{A}$. $\mathrm{Vu}$, for technical assistance. Our thanks are due to K. Buxbaum, T. Luchik and R. Manvi for valuable advice and encouragement. We acknowledge J. Edens, P. Koen and J. Kulleck, for assistance performing the electron microscopy, and M. Wiedeman for $\gamma$-radiation analyses.

\section{REFERENCES}

Anonymous (1980). NASA Standard Procedures for the Microbiological Examination of Space Hardware. Jet Propulsion Laboratory communication NHB 5340.1B, 1980. Pasadena, CA: National Aeronautics and Space Administration.

Anonymous (1989). Contamination control procedure for the tape lift sampling of surfaces. Jet Propulsion Laboratory communication GSFC-TLS-PR-7324-01. Pasadena, CA: National Aeronautics and Space Administration.

Claus, D. \& Berkeley, R. C. W. (1986). Genus Bacillus Cohn, 1872. In Bergey's Manual of Sytematic Bacteriology, vol. 2, pp. 1105-1139. Edited by P. H. A. Sneath, N. S. Mair, M. E. Sharpe \& J. G. Holt. Baltimore: Williams \& Wilkins.

Cole, R. M. \& Popkin, T. J. (1981). Electron microscopy. In Manual of Methods for General Bacteriology, pp. 34-51. Edited by P. Gerhardt, R. G. E. Murray, R. N. Costilaw, E. W. Nester, W. A. Wood, N. R. Krieg \& G. B. Phillips. Washington, DC: American Society for Microbiology.

Coss, J. R. (1999). Test Procedure for Total Ionizing Dose Radiation Testing of Piece-Parts. \# D-15827. Pasadena, CA: National Aeronautics and Space Administration.
Ezaki, T., Hashimoto, Y. \& Yabuuchi, E. (1989). Fluorometric deoxyribonucleic acid-deoxyribonucleic acid hybridization in microdilution wells as an alternative to membrane filter hybridization in which radioisotopes are used to determine genetic relatedness among bacterial strains. Int J Syst Bacteriol 39, 224-229.

Fox, G. E., Wisotzkey, J. D. \& Jurtshuk, P., Jr (1992). How close is close. 16S rRNA sequence identity may not be sufficient to guarantee species identity. Int J Syst Bacteriol 42, 166-170.

Johnson, J. L. (1981). Genetic characterization. In Manual of Methods for General Bacteriology. pp. 450-472. Edited by P. Gerhardt, R. G. E. Murray, R. N. Costilaw, E. W. Nester, W. A. Wood, N. R. Krieg \& G. B. Phillips. Washington, DC: American Society for Microbiology.

Kämpfer, P. (1994). Limits and possibilities of total fatty acid analysis for classification and identification of Bacillus species. Syst Appl Microbiol 17, 86-98

Nicholson, W. L. \& Setlow, P. (1990). Sporulation, germination and outgrowth. In Molecular Biological Methods for Bacillus, pp. 391-450. Edited by C. R. Harwood \& S. M. Cutting. Chichester: Wiley.

Nicholson, W. L., Munakata, N., Horneck, G., Melosh, H. J. \& Setlow, P. (2000). Resistance of Bacillus endospores to extreme terrestrial and extraterrestrial environments. Microbiol Mol Biol Rev 64, 548572.

Priest, F. G. (1993). Systematics and ecology of Bacillus. In Bacillus subtilis and other Gram-positive Bacteria, pp. 3-33. Edited by A. L. Sonenshein, J. A. Hoch \& R. Losick. Washington, DC: American Society for Microbiology.

Puleo, J. R., Oxborrow, G. S., Fields, N. D., Herring, C. M. \& Smith, L. S. (1973). Microbiological profiles of four Apollo spacecraft. Appl Microbiol 26, 838-845.

Puleo, J. R., Favero, M. S., Oxborrow, G. S. \& Herring, C. M. (1975). Method for collecting naturally occurring airborne bacterial spores for determining their thermal resistance. Appl Microbiol 30, 786-790.

Puleo, J. R., Fields, N. D., Bergstrom, S. L., Oxborrow, G. S., Stabekis, P. D. \& Koukol, R. (1977). Microbiological profiles of the Viking spacecraft. Appl Environ Microbiol 33, 379-384.

Riesenman, P. J. \& Nicholson, W. L. (2000). Role of the spore coat layers in Bacillus subtilis spore resistance to hydrogen peroxide, artificial UV-C, UV-B and solar UV radiation. Appl Environ Microbiol 66, 620-626.

Ringelberg, D. B., Townsend, G. T., DeWeerd, K. A., Suflita, J. M. \& White, D. C. (1994). Detection of the anaerobic dechlorinating microorganism Desulfomonile tiedjei in environmental matrices by its signature lipopolysaccharide branched-long-chain hydroxy fatty acids. FEMS Microbiol Ecol 14, 9-18.

Ruimy, R., Breittmayer, V., ElBaze, P., Lafay, B., Boussemart, O., Gauthier, M. \& Christen, R. (1994). Phylogenic analysis and assessment of the genera Vibrio, Photobacterium, Aeromonas, and Plesiomonas deduced from small-subunit rRNA sequences. Int J Syst Bacteriol 44, 416-426.

Satomi, M., Kimura, B., Mizoi, M., Sato, T. \& Fujii, T. (1997). Tetragenococcus muriaticus sp. nov., a new moderately halophilic lactic acid bacterium isolated from fermented squid liver sauce. Int $J$ Syst Bacteriol 47, 832-836.

Schaeffer, P., Millet, J. \& Aubert, J.-P. (1965). Catabolic repression of bacterial sporulation. Proc Natl Acad Sci U S A 54, 704-711.

Stackebrandt, E. \& Goebel, B. M. (1994). A place for DNA-DNA reassociation and $16 \mathrm{~S}$ rRNA sequence analysis in the present species definition in bacteriology. Int J Syst Bacteriol 44, 846-849.

Swofford, D. (1990). PAUP: phylogenetic analysis using parsimony, version 3.0. Computer program distributed by the Illinois Natural History Survey, Champaign, IL, USA. 
Venkateswaran, K., Dohmoto, N. \& Harayama, S. (1998). Cloning and nucleotide sequence of the gyrB gene of Vibrio parahaemolyticus and its application in detection of the pathogen in shrimp. Appl Environ Microbiol 64, 681-687.

Venkateswaran, K., Moser, D. P., Dollhopf, M. E. \& 10 other authors (1999). Polyphasic taxonomy of the genus Shewanella and description of Shewanella oneidensis sp. nov. Int J Syst Bacteriol 49, 705-724.
Venkateswaran, K., Satomi, M., Chung, S., Kern, R., Koukol, R., Basic, C. \& White, D. (2001). Molecular microbial diversity of a spacecraft assembly facility. Syst Appl Microbiol 24, 311-320.

Woese, C. R. (1987). Bacterial evolution. Microbiol Rev 51, 221-271. Yamada, S., Ohashi, E., Agata, N. \& Venkateswaran, K. (1999). Cloning and nucleotide sequence analysis of gyrB of Bacillus cereus, $B$. thuringiensis, B. mycoides and B. anthracis and their application to the detection of B. cereus in rice. Appl Environ Microbiol 65, 1483-1490. 